\title{
About the International Decade for Natural Disaster Reduction
}

— La décennie internationale pour la réduction des catastrophes naturelles —

\author{
by Francesco Pisano \\ Chef, Management Support Unit \\ IDNDR Secretariat
}

\section{Drought, desertification, and floods are a cause of Natural Disasters. The IDNDR develops a culture of prevention to protect the water resources from disasters.}

\section{I $\square$ INTRODUCTION}

To encourage people to protect communities from natural disasters, the United nations launched the International decade for Natural Disaster Reduction (IDNDR, 1990-2000). The objective of IDNDR is to reduce, through concerted international action, the loss of life, property damage, and social and economic disruption caused by natural disasters, especially in developing countries. The World Conference on Natural Disaster Reduction (Yokohama, 23-27 May 1994) was an important milestone in IDNDR's awareness building process.

IDNDR works through IDNDR National Committees and Focal Points, which exist in 138 countries. The IDNDR Secretariat is in Geneva, Switzerland. The IDNDR Scientific and Technical Committee is an advisory body of 25 experts from various fields from around the world. A UN Inter-Agency Standing Committee on IDNDR meets regularly, as well as a contact group of Geneva-based diplomatic missions. A Global Forum of NGOs for Disaster Reduction was founded at the World Conference on Natural Disaster Reduction.

IDNDR Program Plan for 1998-1999 is built around five primary themes : hazard, vulnerability and risk assessment, early warning issues, disasters and sustainable development, political and public policy commitment, shared knowledge and technology transfer.

These themes serve to structure and focus an evaluation of the accomplishments of IDNDR, assess remaining gaps, and make proposals for concerted, effective application of disaster reduction strategies after the year 2000 . The implementation of this plan is coordinated by the IDNDR Secretariat and implemented jointly through contributions of all partners in IDNDR.

\section{Goals}

The goals established at the start of IDNDR are as follows : 1. To improve the capacity of each country to mitigate the effects of natural disasters, in the assessment of disaster damage potential and in the establishment of early warning systems and disaster-resistant capabilities,
2. To devise appropriate guidelines and strategies for applying existing scientific and technical knowledge,

3. To foster scientific and engineering endeavour aimed at adressing critical gaps in knowledge,

4. To disseminate existing and new technical information,

5. To develop measures for the assessment, prediction, prevention and mitigation of natural disasters through programmes of technical assistance and technology transfer, education and training, and to evaluate the effectiveness of programmes.

\section{Targets}

Three programming targets have been established for IDNDR by its Scientific and Technical Committee. These targets form a basis to assess achievements of IDNDR by the beginning of the 21st Century. By the year 2000, all countries should have in place :

1. Comprehensive national assessments of risks from natural hazards integrated into development plans,

2. Mitigation plans of practical measures for application at national and local levels that adress long-term disaster prevention ; preparedness and community awareness.

3. Ready access to warning systems at global, regional, national and local levels.

\section{1 IDNDR ACTION PLAN 1998-1999}

\subsection{Objectives of the Action Plan}

Consolidation : compilation and reporting accomplishments in hazard awareness and disaster reduction activities, internationally and within individual countries and organizations between 1990 and 1999.

Platform for the Future : to recommend functions and institutional mechanisms needed for continued international and national commitments to risk management practices for disaster reduction into the 21 st century.

Closing events : a set of recommmendations will be made to ECOSOC in July 1999 prior to the 54th session of the United Nations General Assembly. Concluding technical and programme issues or recommendations related to priority themes for action will be consolidated and finalized at a concurrent IDNDR Programme Forum, with multi-sectoral and regional representation, in Geneva.

Overall Indicator of Success : the inclusion of global mechanisms and facilities to sustain international commitment and policies, resources and dissemination of information for disaster reduction in the United Nations "Millennium Assembly" in the year 2000 . 


\subsection{Priority activities and implementation arrangements}

National activities, exercised through efforts of national commitees, official authorities and political commitment, emphasized or adapted as most appropriate for a better local involvement : inter alla through public information and education programmes, coordinated by national authorities and national IDNDR committees or focal points, to :

document accomplishments during the Decade through final Country Reports, identify and publicize lessons learned and benefits of disaster reduction, identify list of priority national projects for concluding phase of decade, plan activities for remaining annual promotional campaigns, develop, fund or commit to national disaster reduction strategies of the 21 st century.

Regional activities, implemented by regional IDNDR partner organizations and promoted by the STC members through institutionalized support and resources to encourage the exchange of national technical, programming and organizational experience between individual countries and international political and economic interests.

International activities, which encourage regional mobilization, cross-cutting institutional relationships and the development of national capabilities for action, through United Nations Agencies and other international organizations, coordinated by the IDNDR Secretariat to :

1. document global accomplishments in disaster reduction since 1990 to enable permanent reference and opportunity for dissemination to specific interest groups. An IDNDR website of sources, institutions and sites for disaster reduction information will contribute to this goal,

2. review the status of international accomplishment for disaster reduction at the close of 1999 through a Final Report by the IDNDR Scientific and technical Committee, with reference to the five primary themes of the closing process, also referring to original goals of the decade augmented by the principles of the Yokohama Conference,

3. recommend institutional mechanisms for global and national commitment to hazard awareness and risk management practices for disaster reduction in the 21 st century through recommendations presented by member states to the ECOSOC meeting in July 1999 for the 54th United Nations General Assembly,

4. publish a commemorative volume, Natural Disaster reduction through commercial interest to promote the continuation of the goals and aims of the Decade, and a technical and scientific series, to provide an institutional reference of leading research.

\section{III 日 WATER : TOO MUCH... TOO LITTLE... LEA- DING CAUSE OF NATURAL DISASTERS}

The 1997 IDNDR World Disaster reduction Campaign focused on the need to build a "culture of prevention" to protect the world's water resources from disasters. World Disaster reduction day is observed on the second Wednesday in October, and countries around the world organize events to raise awareness about what we can do to make communities safer - before disater strikes. Drought and desertification are on the rise. Desertification affects one fourth of the earth's land and costs $\$ 42$ billion each year in lost productivity, notes the United Nations Development programme's 1996 Human Development Report. Poor land management pratices are a major contributor, including overgrazing (grazing areas account for $90 \%$ of desertified lands), deforestation, overcultivation (leading to erosion) and poor irrigation drainage.

Floods are growing more quickly than other disasters. Rapid development is changing local ecosystems, increasing flood risks. In urban areas, for example, the use of concrete has changed the capacity of soil to absorb water, leading to flash floods. Yet another cause for increasing damage from floods has to do with location : more people are crowded along river banks, forced into cities (sometimes because of drought) at a rate too fast for cities to absorb them. The rise in flash floods is also partly due to deforestation, which contributes to hillside erosion and makes people vulnerable to landslides triggered by heavy rains. While drought is the leading killer, with nearly 74000 reported deaths in 1996, floods are the most frequent and cause most economic losses. Few countries are spared from floods - no even those in desert areas. Even in Africa, where drought is the most frequent disaster, floods and high-wind disasters rank second. Between 1991 and 1995 floods caused nearly \$203 billion in losses - almost half of total economic damages caused by disasters (Source : 1997 World Disasters report, International Federation of red Cross and red Crescent Societies). But while floods and drought are the main water-related disasters, other water-related disasters include fires (a risk in dry areas) and landslides, which can be triggered by water-logged soil (they are also triggered by earthquakes and volcanic eruptions). Flood risks can come from the coasts (hurricanes or tsunamis) or from rivers.

\section{Some solutions}

Regional cooperation to reduce water-related disasters is important. Disasters know no borders : floods and droughts often affect several countries at once. 300 river basins, for example, straddle national borders. How much water is extracted from rivers and how they are channelled is no longer the issue of a local community or just one country.

In Costa Rica, community early warning systems set up in 1991 along the Atlantic Coast are saving lives and property from floods. Since the system has been established, the region has experienced the most serious floods in over 70 years. Despite this fact, only a few people have died from floods. The system monitors hydrometeorological and geological risks, with 32 monitoring posts located strategically in rivers. The posts are oufitted with gauges to measure rainfall and river levels, as well as communications equipment. The success of the system lies especially in the fact community members operate and manage it. In this area of largely indigenous communities, local participation ensures that messages are understood and acted upon. In 1997, the El Nino phenomenon raised the temperature of the pacific Ocean around the equator, and floods and drought have affected many countries around the world. Many of the affected countries are taking measures to mitigate the impact foreseen for 1998, by setting up high-level committees to take action, assigning funds for risk assessment and mapping, and establishing public works for drainage, early warning systems, and preparedness training sessions. 